2 Improved Anthropogenic $\mathrm{SO}_{2}$ Retrieval from High-

3 spatial-resolution Satellite and its Application during

\title{
the COVID-19 Pandemic
}

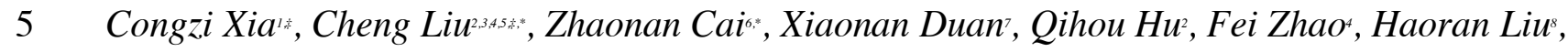
Xiangguang Ji', Chengxin Zhang, ${ }^{4}$, Liu $^{6}$

7 School of Earth and Space Sciences, University of Science and Technology of China, Hefei 230026, China Mechanics, Chinese Academy of Sciences, Hefei 230031, China

$11{ }^{3}$ Center for Excellence in Regional Atmospheric Environment, Institute of Urban Environment,

$13{ }^{4}$ School of Engineering Science, University of Science and Technology of China, Hefei 230026, 
15 sKey Laboratory of Precision Scientific Instrumentation of Anhui Higher Education Institutes,

16 University of Science and Technology of China, Hefei 230026, China

17 Key Laboratory of Middle Atmosphere and Global Environment Observation, Institute of

18 Atmospheric Physics (IAP), Chinese Academy of Sciences, Beijing 100029, China

19 'Bureau of Frontier Sciences and Education, Chinese Academy of Sciences, Beijing 100864,

China

21 snstitute of Physical Science and Information Technology, Anhui University, Hefei 230601, China

23 School of Environmental Science and Optoelectronic Technology, University of Science and Technology of China, Hefei 230026, China

25 These authors contributed equally to this work

26 Correspondence authors: Cheng Liu (chliu81@ustc.edu.cn) and Zhaonan Cai

27 (caizhaonan@mail.iap.ac.cn)

28

2933 Pages, 16 Figures, 3 Table

30

31

32 
34 One MAX-DOAS instrument is installed in the Environmental Protection Bureau of Hefei (HF,

$3531.78 \mathrm{~N}, 117.20 \mathrm{E}, 20 \mathrm{~m}$ a.g.1.); it is coupled with one spectrometer (Princeton instrument, USA), 36 which is adopted to measure spectra in UV (300 to $370 \mathrm{~nm}$ ) wavelength range ${ }^{\text {. The spectral }}$

37 resolution is $0.35 \mathrm{~nm}$. The measurement period used for verification ranges from June 2018 to

38 February 2019. The other three MAX-DOAS instruments are located in Beijing (Chinese Academy 39 of Meteorological Sciences (CAMS, 39.9472 N, 116.3206 E, 42 m a.g.1.), University of Chinese 40 Academy of Science (UCAS, 40.4080 N, 116.6750 E, 18 m a.g.1.) and Nancheng (NC, 39.7810 N,

$41 \quad 116.1270$ E, $12 \mathrm{~m}$ a.g.l.)). They are coupled with a spectrometer (Avaspec-UL2048L-USB2). The 42 spectral range is $300-460 \mathrm{~nm}$ with a spectral resolution of $0.6 \mathrm{~nm}^{2}$.

43 QDOAS spectral fitting software suite developed by BIRA-IASB (http://uv44 vis.aeronomie.be/software/QDOAS/) is applied to retrieve the differential slant column densities 45 (DSCDs) of trace gases. In this study, the "geometric approximation" method is employed to 46 estimate a tropospheric $\mathrm{AMF}{ }^{13}$. The tropospheric $\mathrm{VCD}\left(V C D_{\text {trop }}\right)$ can be expressed as:

$47 \quad V C D_{\text {trop }}=\frac{D S C D_{\alpha}}{D A M F_{\alpha}}=\frac{D S C D_{\alpha}}{1 / \sin \alpha^{-1}}$ 
Text S2: Retrieval Algorithm

$57 \quad Y$ is the cost function comprising the measured spectrum, $R(X)$ is the simulated spectrum, $X$ is

58 the retrieved vector, $X_{a}$ is the a priori state vector, $S_{y}$ is the measurement error covariance matrix

59 and $S_{a}$ is the a priori uncertainty covariance matrix. $K$ denotes the weighting function matrix with

60 state elements, which is calculated from VLIDORT.

61 The iteration and cost functions are expressed as follows:

$62 \quad X_{i+1}=X_{i}+\left(K_{i}^{T} S_{y}^{-1} K_{i}+S_{a}^{-1}\right)^{-1}\left[K_{i}^{T} S_{y}^{-1}\left(Y-R\left(X_{i}\right)\right)-S_{a}^{-1}\left(X_{i}-X_{a}\right)\right]$

$63 \quad \chi^{2}=\left\|S_{y}^{-\frac{1}{2}}\left\{K_{i}\left(X_{i+1}-X_{i}\right)-\left[Y-R\left(X_{i}\right)\right]\right\}\right\|_{2}^{2}+\left\|S_{a}^{-\frac{1}{2}}\left(X_{i}-X_{a}\right)\right\|_{2}^{2}$

64 The retrieved vector $X$ comprises the $\mathrm{SO}_{2}$ vertical column, $\mathrm{HCHO}$ and $\mathrm{BrO}$ vertical column,

65 ozone profile on 24 vertical grids, effective cloud fraction and surface albedo, two wavelength

66 shifts (between radiances and irradiances and between radiances and ozone cross sections), a

67 scaling factor for Ring effect and a polynomial to reduce the low-frequency residuals between

68 radiance and irradiance.

69 Cloud pressure is taken from the Sentinal-5 Precursor (S-5P) operational cloud products ${ }^{4}$. The

70 ozone profile is split into 24 layers. The a priori data is acquired according to the tropopause-based

71 ozone profile climatology, capable of presenting the variations in the upper troposphere and lower

72 stratosphere ${ }^{5}$. The initial ozone profile originates from the previous pixel results to decrease the

73 retrieval time. For the ozone cross section, the data are derived from the work of Brion et al. ${ }^{6}$ at

74 four temperatures $(218,228,243,295 \mathrm{~K})$. Temperature profile, tropopause pressure and surface

75 pressure $\left(1.0^{\circ} \times 1.0^{\circ}\right)$ are harvested according to the daily National Centers for Environmental

76 Prediction (NCEP) reanalysis data. 
77 In this study, the monthly average $\mathrm{SO}_{2}$ profiles in 2017 simulated by the global three-dimensional

78 chemical transport model (GEOS-Chem) are applied as a priori $\mathrm{SO}_{2}$ profiles ${ }^{7}$. The GEOS-Chem is

79 based on an inventory with power-plant emissions in China from a Chinese power sector database supported by

80 Chinese Ministry of Environmental Protection ? The a priori $\mathrm{SO}_{2}$ profiles are on a grid of $2^{\circ} \times 2.5^{\circ}$

81 (latitude $\times$ longitude). In $\mathrm{OE}$ algorithm, the $\mathrm{SO}_{2}$ columns vary in the retrieval iteration and exhibits

82 a constant $\mathrm{SO}_{2}$ profile shape. The $\mathrm{SO}_{2}$ cross sections depend on the temperature and are referenced

83 from Bogumil et al. ${ }^{8}$.

84 In the mentioned spectral range, $\mathrm{BrO}$ and $\mathrm{HCHO}$ also absorb interference. Thus, vertical

85 columns of $\mathrm{BrO}$ and $\mathrm{HCHO}$ are covered in the state vector and retrieved simultaneously.

86 Stratospheric $\mathrm{BrO}$ profiles originate from climatologic transport model simulations "; besides, the

87 cross sections are referenced from Wilmoyth et al. ${ }^{10}(228 \mathrm{~K}) . \mathrm{HCHO}$ tropospheric profiles are from

88 monthly GEOS-Chem climatology, and the cross sections are referenced from Meller and

89 Moortgat ${ }^{\prime \prime}$.

90

91

92

93

94

95

96

97

98

99

100 
102 The spectral fitting residuals exhibit systematic low-order biases in the focused spectral range.

103 This study adopts "soft calibration" to remove the systematic biases ${ }^{5,1,2,13}$. Soft Calibration is the 104 ratio of the measured and modelled radiance. And the modelled radiance is from VLIDORT 105 simulations after the first iteration. The ozone profiles inputted in VLIDORT comprise two parts, 106 which are climatological ozone profile from McPeter ${ }^{14}$ for pressure $>215 \mathrm{hPa}$ and daily zonal 107 mean ozone profile for pressure $<215 \mathrm{hPa}$. The correction is determined with the observations at 108 latitude between $15^{\circ} \mathrm{N}$ and $15^{\circ} \mathrm{S}$, leading to the effective cloud fraction of $<10 \%$ and the solar 109 zenith angle (SZA) of $<40^{\circ}$. For more details, please refer to F. Zhao et al. ${ }^{15}$. 
125 Instrument slit function is of high significance to the retrievals. We convolve high spectral 126 resolution solar spectrum with instrument slit function for wavelength calibration and convolve 127 trace gas cross sections with instrument sit function to simulate radiance spectra. S-5P Pre128 Operations Data Hub provided preflight TROPOMI instrument spectral response functions (ISRFs) 129 (version 1.0.0 (v1.0.0) and v3.0.0). Preflight TROPOMI ISRFs v1.0.0 were measured on ground 130 for each CCD pixel (68 band centers and 450 cross-track positions) in May 2015 (TROPOMI ISRF 131 Calibration Key Data v1.0.0). Subsequently, the TROPOMI ISRFs v3.0.0 was released on 1 April 1322018 for respective CCD pixel (79 band centers and 450 cross-track positions) 133 (http://www.tropomi.eu/data-products/isrf-dataset/).

134 The variation of the instrument slit function over time should be considered ${ }^{16}$. Bak et al. ${ }^{17}$ 135 reported that Gaussian and super Gaussian functions can reduce the systematic biases of ozone in 136 tropics and mid-latitudes. In this study, the analytical slit functions are standard Gaussian and super 137 Gaussian functions, since they can easily fit the shapes of TROPOMI ISRFs v1.0.0 and v3.0.0 (SI 138 Figure S3) The analytical slit functions are determined by fitting the measured TROPOMI 139 irradiance and simulated solar irradiance from high spectral resolution solar reference spectrum ${ }^{18}$. 140 For more details concerning analytical slit functions, we reference Beirle et al. ${ }^{19}$ and Bak et al. ${ }^{5}$.

141 The analytical slit functions are determined by fitting the measured TROPOMI irradiance and 142 simulated solar irradiance from high spectral resolution solar reference spectrum ${ }^{18}$.

$143 \quad I_{s}(\lambda)=A I_{0}(\lambda+\Delta \lambda) \times \sum P_{i}\left(\lambda-\lambda_{\text {avg }}\right)^{i}$

$144 I_{0}$ denotes the convolved high spectral resolution solar reference spectrum with instrument slit 145 function. To simulate the solar irradiance, the wavelength shift and squeeze, $\lambda+\Delta \lambda$, baseline 
146 factor $P_{i}$ (five-order polynomial), and the scaling factor $A$ (two-order polynomial) are considered.

$147 A$ and $P_{i}$ represent the low frequency differences between measured and simulated irradiance.

148 The variations in both FWHMs of TROPOMI ISRFs v1.0.0 and v3.0.0 over cross-track positions

149 are less than $0.05 \mathrm{~nm}$ at the center wavelength in the focused spectral range (SI Figure S4a). The

150 variations in FWHMs over the focused spectral range are negligible in TROPOMI ISRFs v1.0.0,

151 whereas they are significant in TROPOMI ISRFs v3.0.0 (FWHMs largely vary by more than 0.05

$152 \mathrm{~nm}$, SI Figures S3a,b). Thus, we should consider the variations over the cross-track positions and 153 wavelengths.

154 FWHMs of four slit functions almost comply with each other along cross-track positions (SI 155 Figure 4a). On the whole, they rise along the first cross-track position to the last, and the FWHMs 156 of analytical slit functions are narrower than those of TROPOMI ISRFs v1.0.0 and v3.0.0. The 157 FWHMs of TROPOMI ISRFs v1.0.0 $(0.564-0.596 \mathrm{~nm})$ exceed those of TROPOMI ISRFs v3.0.0 $158(0.511-0.591 \mathrm{~nm})$ at the center wavelength in the focused spectral range. The FWHMs of standard 159 Gaussian and super Gaussian functions are more obviously fluctuated along the cross-track 160 positions than those of TROPOMI ISRFs v1.0.0 and v3.0.0. The FWHMs of Standard Gaussian 161 and Super Gaussian functions respectively range from 0.497 to $0.533 \mathrm{~nm}$ and from 0.507 to 0.547 $162 \mathrm{~nm}$. Besides, the shape factor $(K)$ of super Gaussian function fluctuates along the cross-track 163 positions, reaching the value over 2.2. It is therefore suggested that super Gaussian functions 164 exhibit broader peaks and thinner wings, compared with standard Gaussian functions based on the 165 identical slit widths.

166 The average fitting residuals retrieved with TROPOMI ISRFs v3.0.0 are the smallest (less than $1670.5 \%$ ) in all cross-track positions (SI Figure S4b). The average fitting residuals retrieved with 168 TROPOMI ISRFs v1.0.0 are the largest in almost all cross-track positions (larger than $0.5 \%$ ). 
169 Improvements in the correct index in the full spectral resolution ISRFs data set from TROPOMI

170 ISRF v1.0.0 to v3.0.0 can account for the enhancement in the fitting residuals ${ }^{20}$. The average fitting

171 residuals retrieved with analytical slit functions are larger than those retrieved with TROPOMI

172 ISRFs v3.0.0. The examples of four slit functions at left, center and right cross-track positions

173 illustrate that the TROPOMI ISRFs v1.0.0 and v3.0.0 shapes are asymmetrical (SI Figures S3c-e).

174 This study only analyzes the symmetrical Gaussian slit functions. The average fitting residuals at

175 the edges are larger than those at middle cross-track positions (SI Figure S4b), which may be due

176 to larger FOVs at the edges of swath.

177 From April 2018 to September 2019, if standard Gaussian function was used in wavelength

178 calibration, the FWHM would change from 0.515 to $0.520 \mathrm{~nm}$ (by $1 \%$ ) at the center cross-track

179 position. So, the variations of FWHM over time are not required to be considered now. The use of

180 TROPOMI ISRFs v3.0.0 is recommended, instead of that of other slit functions mentioned due to

181 the better fittings between daily irradiance and simulated irradiance. The fitting residuals between

182 measured irradiance and simulated irradiance derived with wavelength-dependent TROPOMI

183 ISRFs v3.0.0 are $-10 \%$ to $10 \%$ for orbit 02453 on April 4th 2018, a data larger than those derived

184 with wavelength-constant instrument slit function. Thus, TROPOMI ISRF v3.0.0 at the center

185 wavelength in the focused spectral range is adopted in the rest of the study.

186

187

188

189

190

191 
192 Table S1. Eight Spectral Channels in TROPOMI

\begin{tabular}{lllll}
\hline Band & $\begin{array}{l}\text { Spectral Range } \\
{[\mathrm{nm}]}\end{array}$ & $\begin{array}{l}\text { Spectral Resolution } \\
{[\mathrm{nm}]}\end{array}$ & $\begin{array}{l}\text { Spectral Sampling } \\
{[\mathrm{nm} / \text { pixel }]}\end{array}$ & Ground-pixel \\
\hline 1 & $270-300$ & 0.5 & 0.065 & 77 \\
2 & $300-330$ & 0.5 & 0.065 & 448 \\
3 & $302-405$ & 0.5 & 0.20 & 450 \\
4 & $405-500$ & 0.5 & 0.20 & 450 \\
5 & $675-735$ & 0.5 & 0.124 & 448 \\
6 & $725-775$ & 0.5 & 0.124 & 448 \\
7 & $2305-2345$ & 0.23 & 0.084 & 215 \\
8 & $2345-2385$ & 0.23 & 0.097 & 215 \\
\hline
\end{tabular}

193

194

195

196

197

198

199

200

201

202

203

204

205

206

207

208 


\begin{tabular}{|c|c|c|}
\hline Parameters & A priori or input data & Cross-section \\
\hline Effective surface albedo & OMI climatology ${ }^{21}$ & \\
\hline Effective cloud fraction & Calculated from $347 \mathrm{~nm}$ radiance & \\
\hline $\mathrm{O}_{3}(24$ layers $)$ & $\begin{array}{l}\text { tropopause-based ozone profile } \\
\text { climatology }\end{array}$ & $\begin{array}{l}\text { Liu et al. }{ }^{22} \text { from Brion et al. }{ }^{6}(218,228,243 \text {, } \\
295 \mathrm{~K})\end{array}$ \\
\hline $\mathrm{SO}_{2}$ vertical column & GEOS-Chem monthly data & Bogumil et al. ${ }^{8}(203,223,243,273,293 \mathrm{~K})$ \\
\hline $\mathrm{BrO}$ vertical column & McLinden et al. ${ }^{23}$ & Wilmouth et al. ${ }^{10}(228 \mathrm{~K})$ \\
\hline HCHO vertical column & GEOS-Chem monthly data & Meller abd Noortgat " (298K) \\
\hline $\begin{array}{l}\text { Wavelength shift between } \\
\text { radiance and irradiance }\end{array}$ & 0 & \\
\hline $\begin{array}{l}\text { Wavelength shift between } \mathrm{O}_{3} \\
\text { cross-section and radiance }\end{array}$ & 0 & \\
\hline Ring effect scaling & 1.9 & Sioris and Evans ${ }^{24}$ \\
\hline
\end{tabular}


222 Table S3. Comparisons of the retrieval methods and settings between SO2-OE and S-5P

223 operational $\mathrm{SO}_{2}$ product

\begin{tabular}{|c|c|c|}
\hline & SO2-OE Product & S-5P Operational Product ${ }^{25}$ \\
\hline Retrieval algorithm & Optical estimation-based algorithm & $\begin{array}{l}\text { Differential optimal absorption } \\
\text { spectrum }\end{array}$ \\
\hline Radiative calibration & "Soft calibration" & No \\
\hline Fitting windows & $310.5-326.0 \mathrm{~nm}$ & $312.0-326.0 \mathrm{~nm}$ \\
\hline $\mathrm{SO}_{2}$ cross-section & $\begin{array}{l}\text { Bogumil et al. }^{8}(203 \mathrm{~K}, 223 \mathrm{~K}, 243 \mathrm{~K} \text {, } \\
273 \mathrm{~K}, 293 \mathrm{~K})\end{array}$ & Bogumil et al. ${ }^{*}(203 \mathrm{~K})$ \\
\hline $\mathrm{O}_{3}$ cross-section & $\begin{array}{l}\text { Brion et al. }{ }^{\circ}(218 \mathrm{~K}, 228 \mathrm{~K}, 243 \mathrm{~K} \text {, } \\
295 \mathrm{~K})\end{array}$ & $\begin{array}{l}\text { Brion et al. }{ }^{6}(228 \mathrm{~K} \text { and } 243 \mathrm{~K}) \text { with } \\
\text { Io correction }+ \text { Pseudo } \mathrm{O}_{3} \text { cross- } \\
\text { section }{ }^{26}\end{array}$ \\
\hline Ring effect & scaling factor to correct Ring effect & $\begin{array}{l}\text { two eigenvectors }{ }^{27} \text { generated for } 20^{\circ} \\
\text { and } 87^{\circ} \text { solar zenith angles using } \\
\text { LIDORT-RRS }\end{array}$ \\
\hline $\mathrm{SO}_{2}$ a priori profile & GEOS-Chem monthly simulations & TM5 daily simulations ${ }^{29}$ \\
\hline Cloud fraction & Calculated from radiance at $347 \mathrm{~nm}^{1230}$ & S-5P operational cloud product ${ }^{31}$ \\
\hline Polynomial & 3-order & 5-order \\
\hline Reference spectrum & Daily measured irradiance spectrum & $\begin{array}{l}\text { Averaged earthshine spectrum of the } \\
5 \text { days around the current day in } \\
\text { Pacific region }\left(10^{\circ} \mathrm{S}-10^{\circ} \mathrm{N}, 160^{\circ} \mathrm{E}-\right. \\
\left.120^{\circ} \mathrm{W}\right)\end{array}$ \\
\hline
\end{tabular}



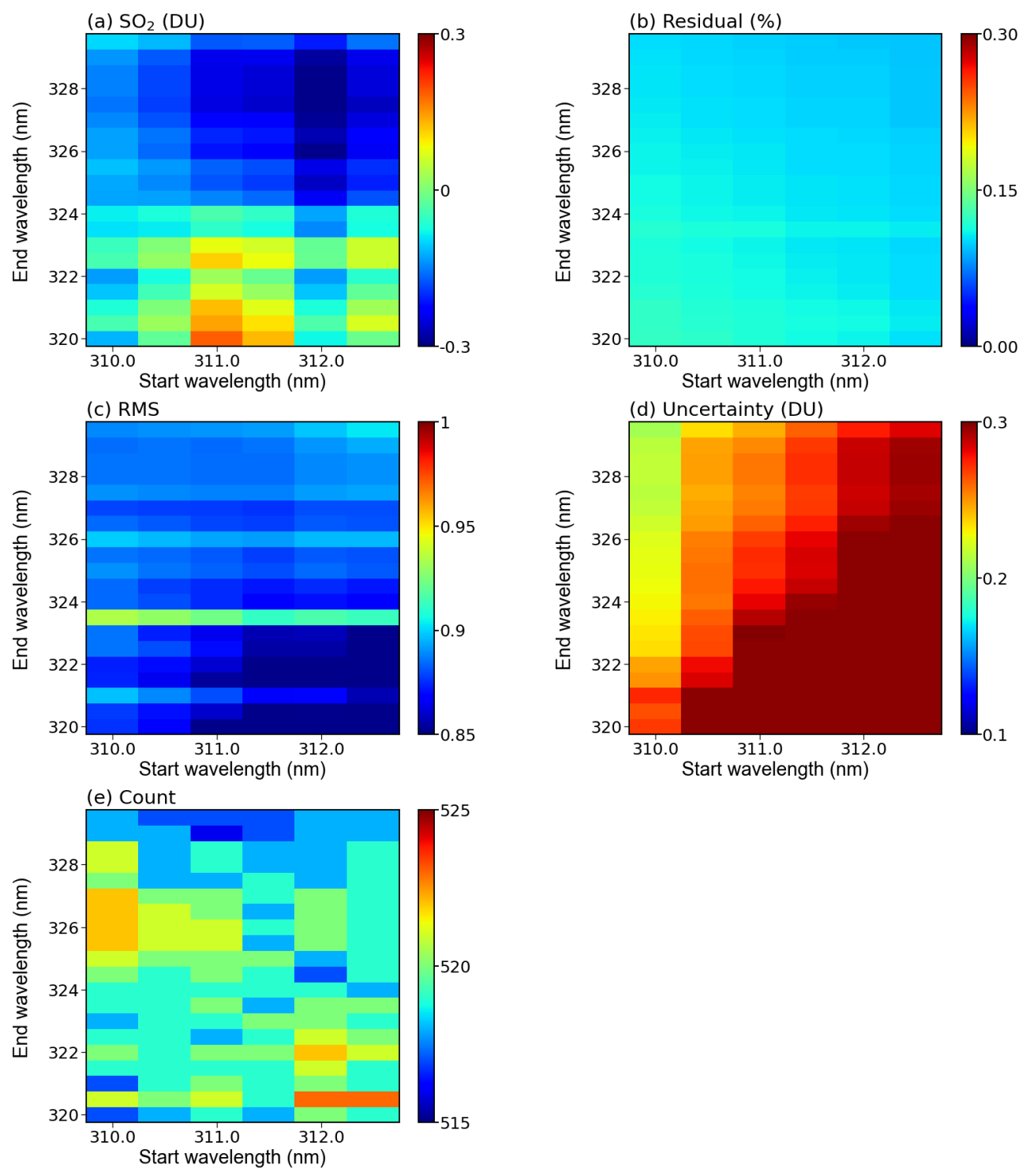

232 Figure S1. Retrieval results from TROPOMI BAND 3 data including (a) $\mathrm{SO}_{2} \mathrm{VCD}$, (b) the fitting

233 residual, (c) RMS, (d) the retrieval uncertainty and (e) the number of pixels successfully retrieved

234 for different fitting windows. The $\mathrm{x}$ and $\mathrm{y}$ axis present the beginning and the end of the fitting

235 window, respectively. The step length of the wavelength is $0.5 \mathrm{~nm}$. 

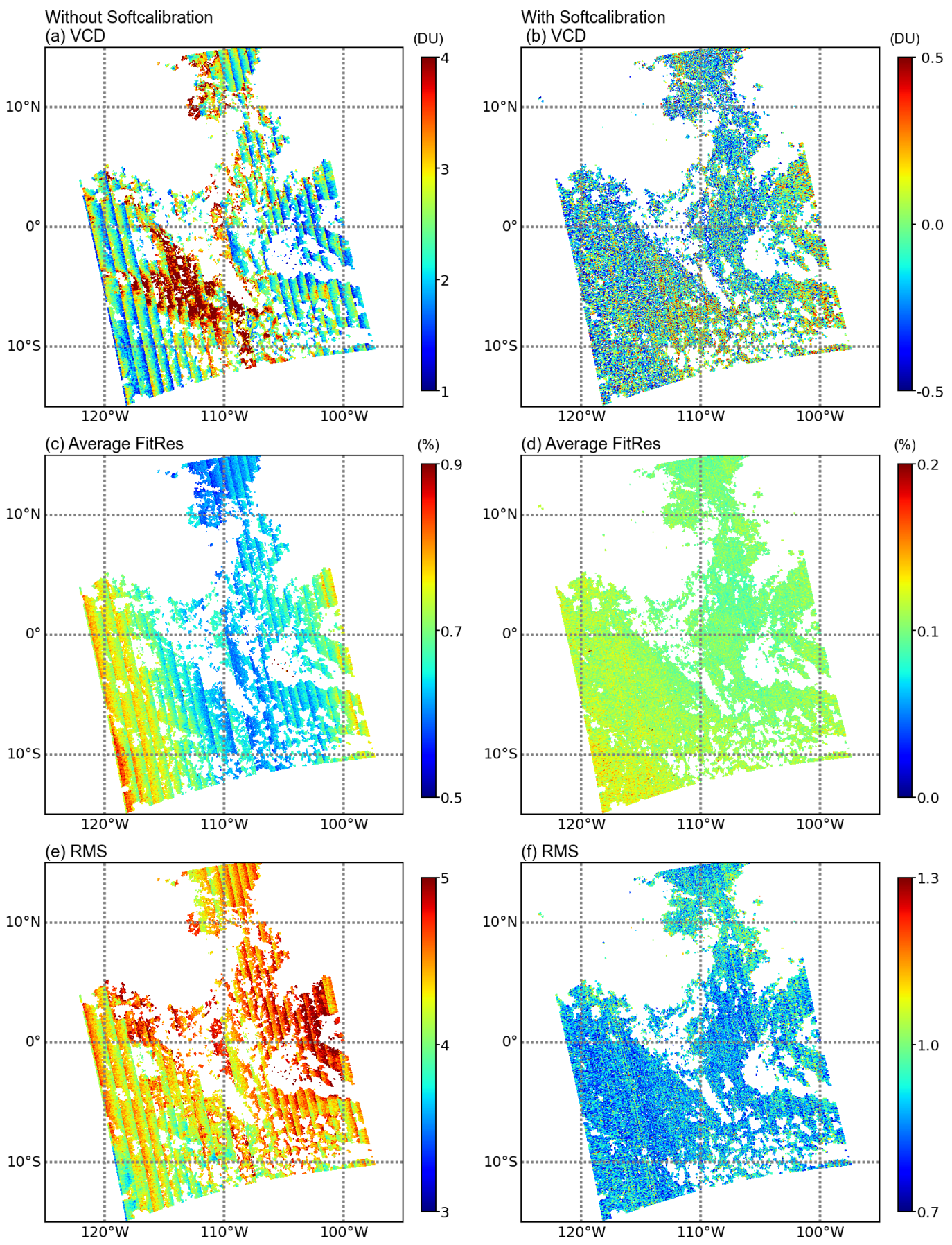

Figure S2. The retrieval results including (a) VCD, (c) average fitting residuals and (e) RMS

241 without the use of "soft calibration" over clean Pacific areas for orbit 02929 on 7 May 2018. Left

242 panels same as the right, but for the results with the use of "soft calibration". 

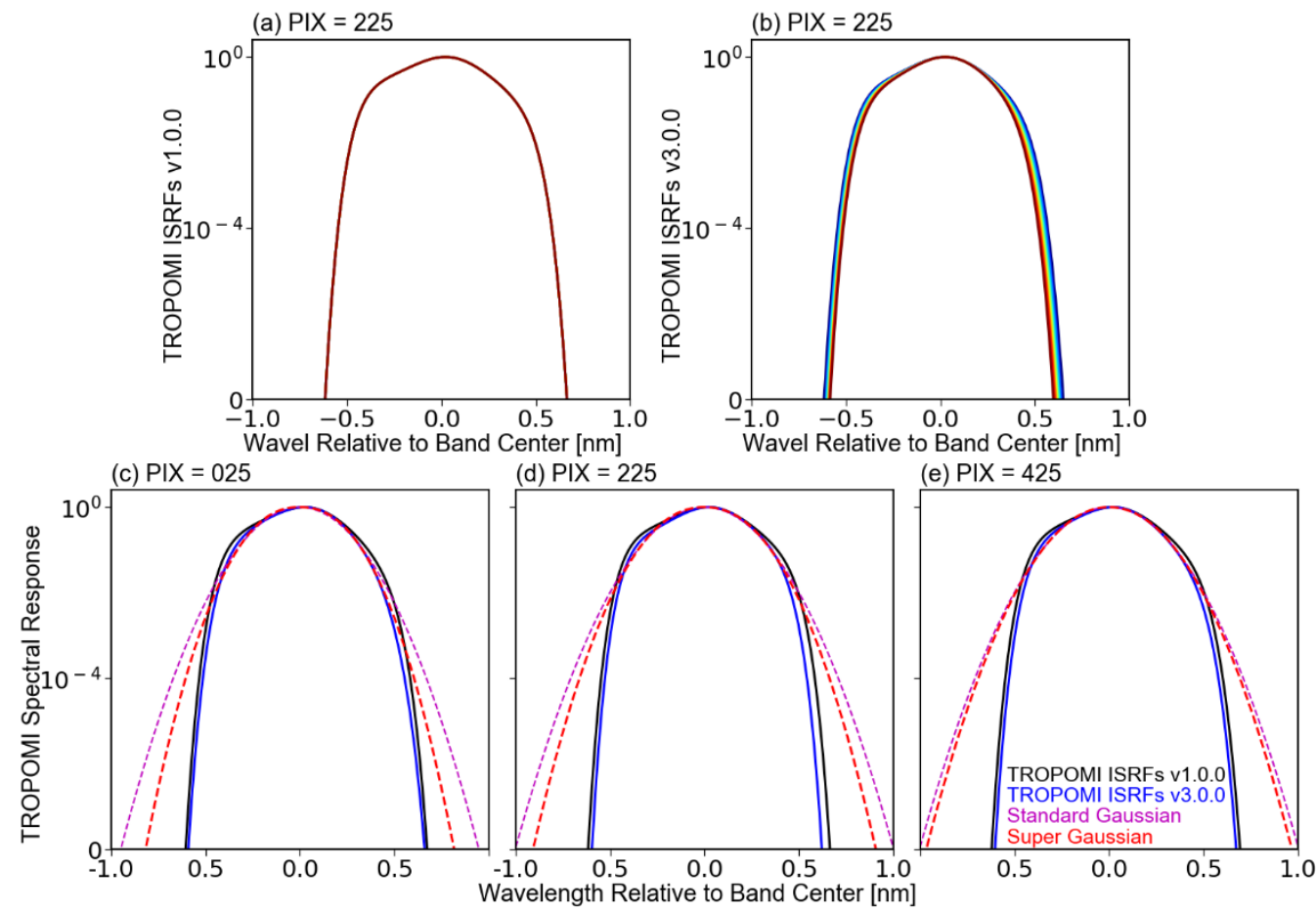

245 Figure S3. The distribution of (a) TROPOMI ISRFs v1.0.0 and (b) TROPOMI ISRFs v3.0.0 at

246 the center of the cross-track positions, with colors meaning from wavelength $310.5 \mathrm{~nm}$ (blue) to

$247326 \mathrm{~nm}$ (red). (c-e) The comparison of TROPOMI ISRFs v1.0.0 (black line), TROPOMI ISRFs

248 v3.0.0 (blue line), Standard Gaussian (magenta dash line) and Super Gaussian (red dash line) at

249 different cross-track positions for orbit 02453 on 4 April 2018. 


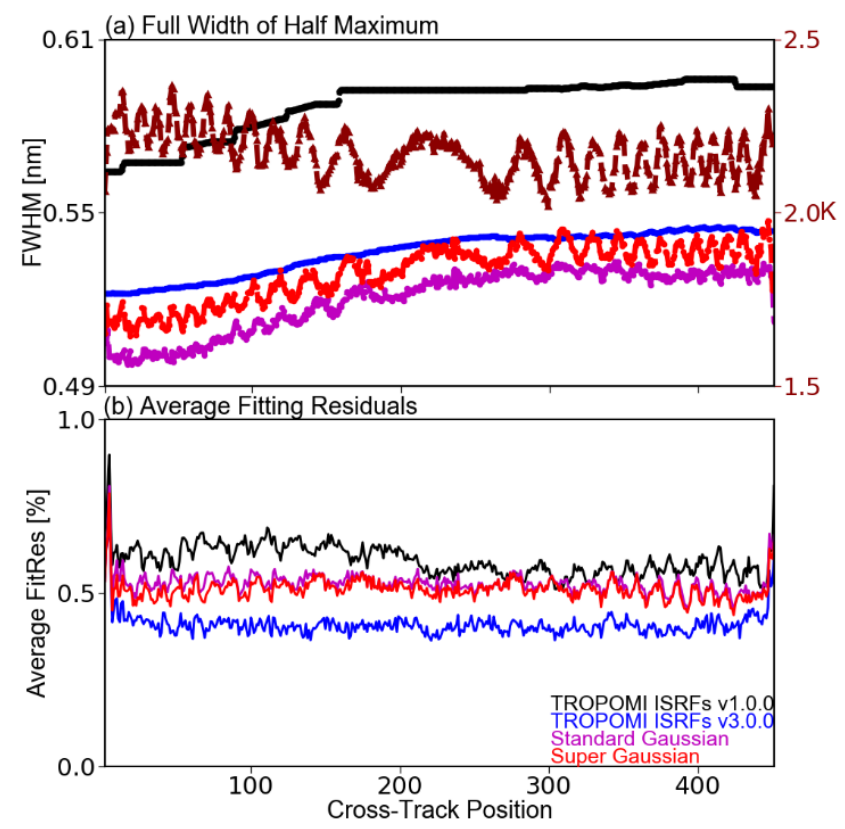

252 Figure S4. (a) The variation of FWHMs with the cross-track positions for TROPOMI ISRFs v1.0.0

253 (black line), TROPOMI ISRFs v3.0.0 (blue line), Standard Gaussian functions (magenta line) and

254 Super Gaussian functions (red line) at band center. The dark red line with triangle marker presents

255 the shape factor of Super Gaussian. (b) same as (a), but for the average relative fitting residuals

256 between simulated and measured irradiance spectra retrieved using these four different kinds of 257 slit functions. The wavelength range we focus on is from 310.5 to $326.0 \mathrm{~nm}$ in the BAND 3 258 irradiance measurements for orbit 02453 on 4 April 2018. 


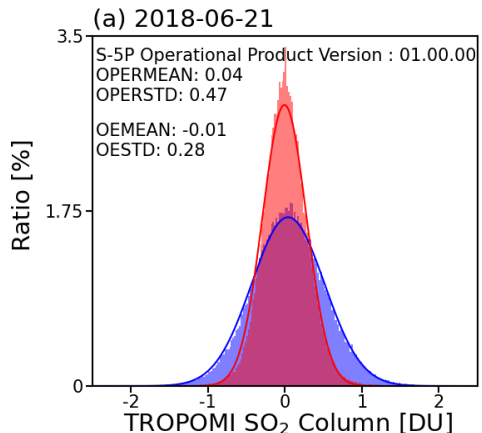

(b) 2019-12-15

(c) 2020-08-07

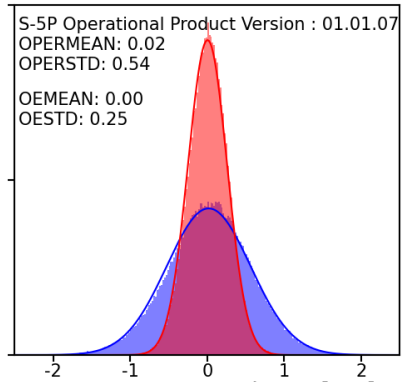

${ }^{-2}$ TROPOMI $\mathrm{SO}_{2}^{-1}$ Column [DU] - Gaussian: S-5P Operational S-5P Operational Product

S-5P Operational Product Version : 02.01 .03 OPERMEAN: 0.13 OPERSTD: 0.68

OEMEAN: -0.01

OESTD: 0.30

OESTD: 0.30
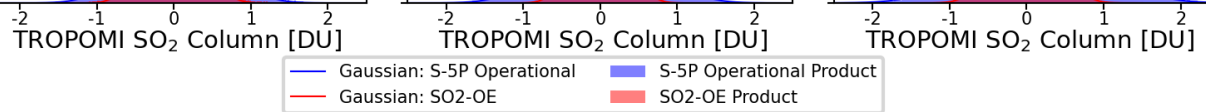

TROPOMI SO $_{2}^{-2}$ Column [DÜ]

264 Figure S5. The frequency of $\mathrm{SO}_{2}$ distribution from $\mathrm{SO} 2-\mathrm{OE}$ product (red) and S-5P operational

265 product (blue) in different versions: (a) 01.00.00, (b) 01.01.07 and (c) 02.01.03, in clean Pacific

266 areas. Red solid line - the Gaussian function fitted by the SO2-OE product, blue solid line - the

267 Gaussian function fitted by the S-5P operational product. The performance measures include the

268 average $\mathrm{SO}_{2}$ column and standard deviation of SO2-OE product (OEMEAN, OESTD) and S-5P

269 operational Product (OPERMEAN, OPERSTD). 

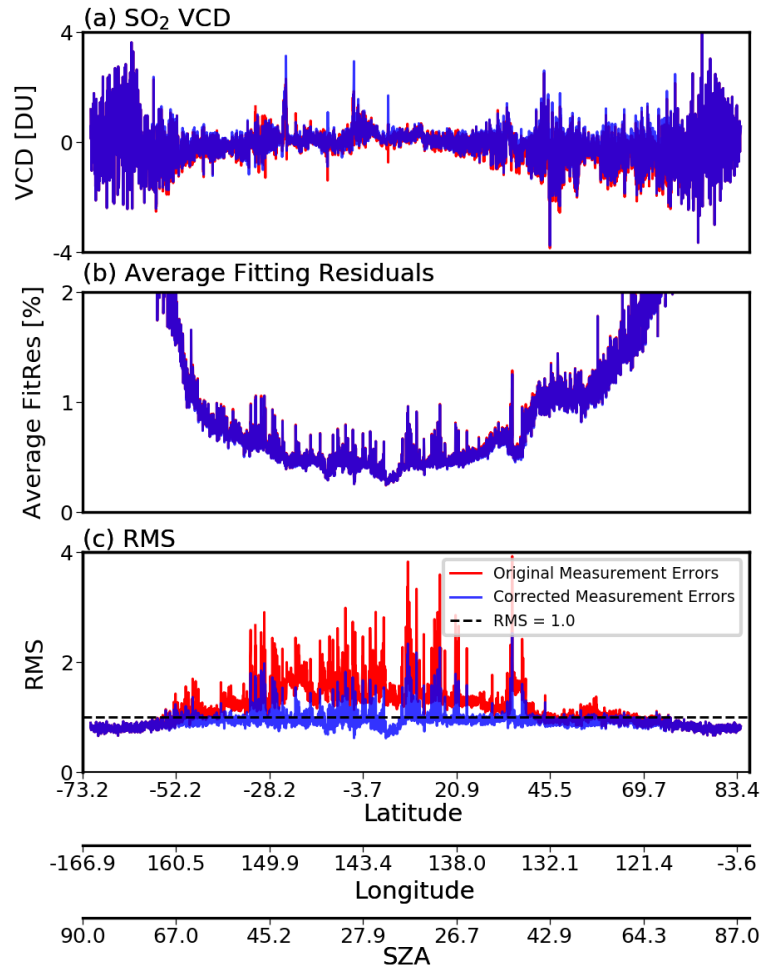

283

284 Figure S6. (a) $\mathrm{SO}_{2}$ columns, (b) average fitting residuals and (c) RMS retrieved from TROPOMI

285 BAND 2 data using original measurement errors (red) and using corrected measurement errors

286 (blue) for orbit 02451 on 4 April 2018 for all pixels on 335th cross-track position. 

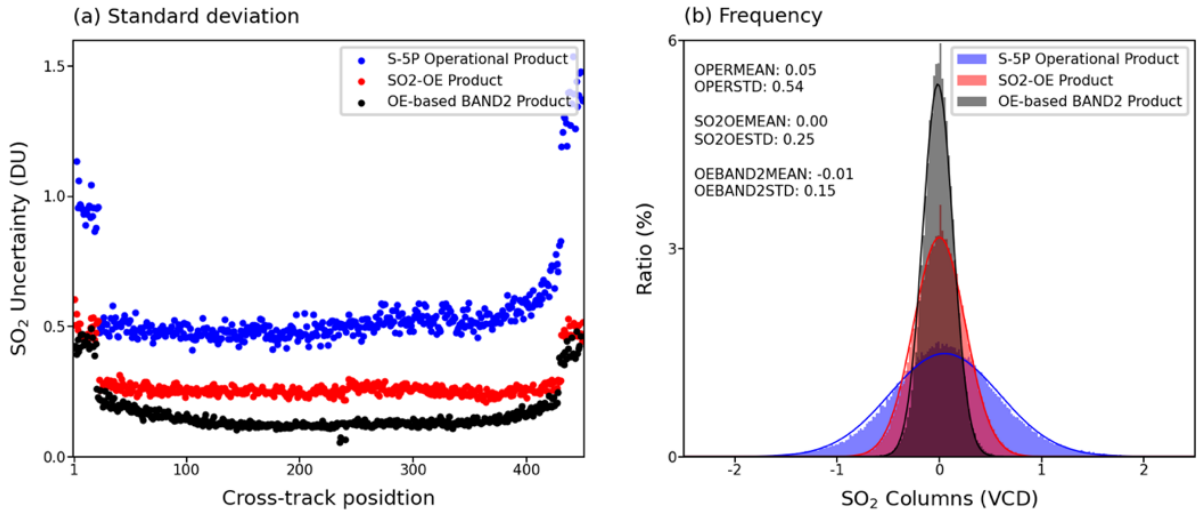

293 Figure S7. (a) The $\mathrm{SO}_{2}$ uncertainties of S-5P operational $\mathrm{SO}_{2}$ product (blue), SO2-OE product (red)

294 and OE-based $\mathrm{SO}_{2}$ retrieval from BAND 2 data (black) as a function of the TROPOMI cross-track

295 position in clean Pacific regions on June 16, 2018. (b) The frequency of $\mathrm{SO}_{2}$ distribution from

296 SO2-OE product (red), S-5P operational product (blue) and OE-based $\mathrm{SO}_{2}$ retrieval from BAND2

297 data (black). The performance measures include the average $\mathrm{SO}_{2}$ column and standard deviation

298 in S-5P operational $\mathrm{SO}_{2}$ Product (OPERMEAN, OPERSTD), SO2-OE product (SO2OEMEAN,

299 SO2OESTD) and OE-based $\mathrm{SO}_{2}$ retrieval from BAND 2 data (OEBAND2MEAN,

300 OEBAND2STD). 

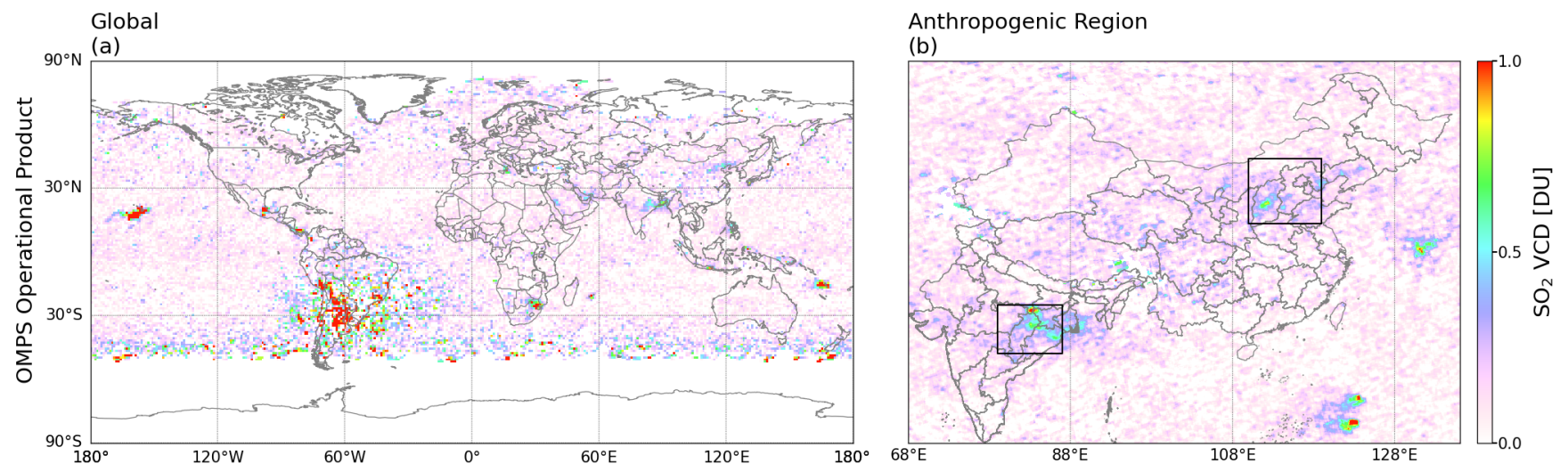

312 Figure S8. (a) Global weekly distribution of $\mathrm{SO}_{2}$ columns (from 6 to12 May 2018) collected from

313 OMPS operational $\mathrm{SO}_{2}$ product. (b) same as (a), but for the monthly average $\mathrm{SO}_{2}$ columns in May

3142018 in China and India. 

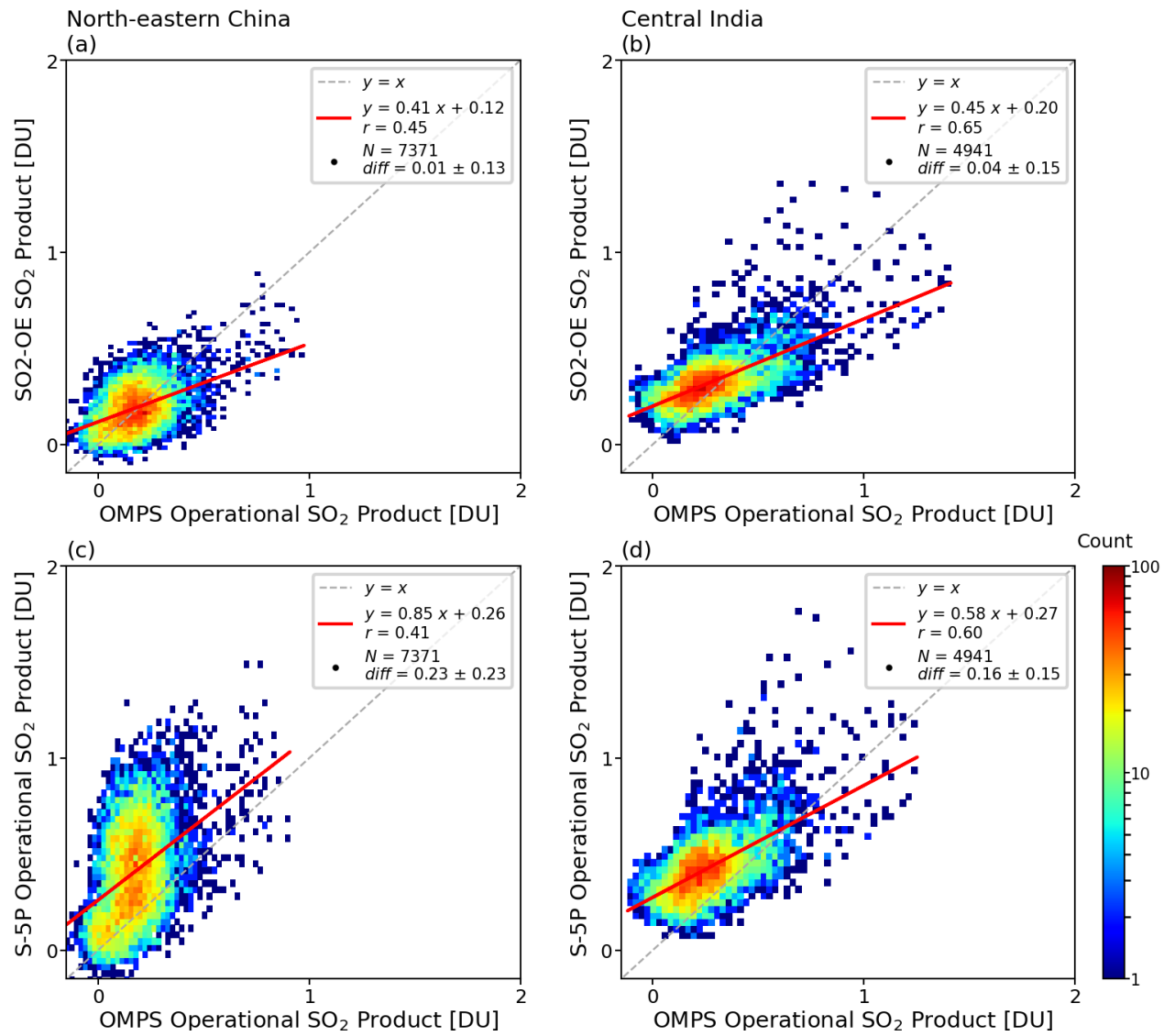

Figure S9. The density scatter plot of $\mathrm{SO}_{2}$ columns collected from $\mathrm{SO} 2-\mathrm{OE}$ product against OMPS operational product in (a) North-eastern China and (b) Central India. (c) and (d) same as (a) and (b), but for the comparison between S-5P operational product and OMPS operational product. 

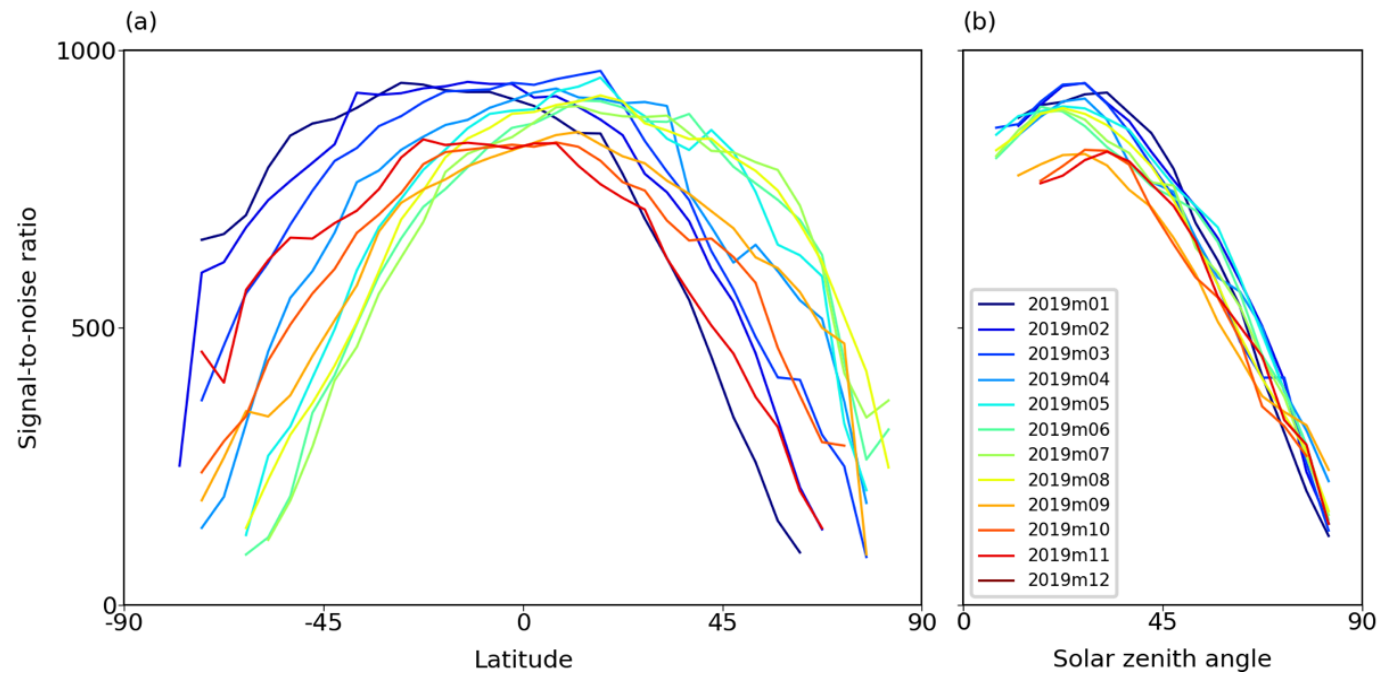

332 Figure S10. Signal-to-noise ratio of TROPOMI BAND 3 radiance as a function of (a) latitudes

333 and (b) solar zenith angles. 


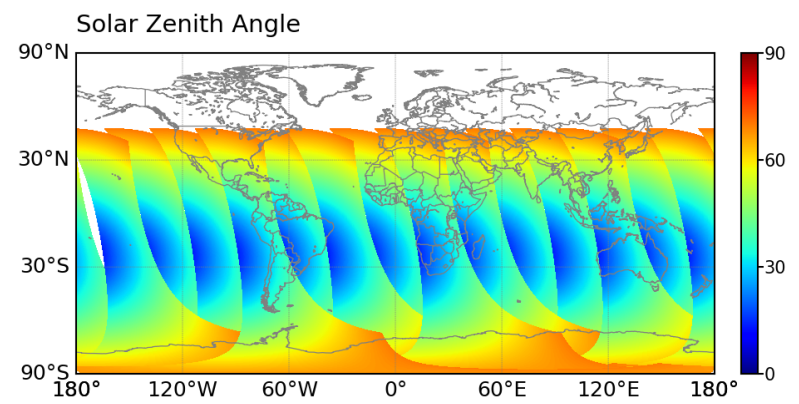

347 Figure S11. Solar zenith angle of TROPOMI measurements on December 5, 2019. 
SO2-OE Product from BAND3 data

(a) Solution Error (DU)

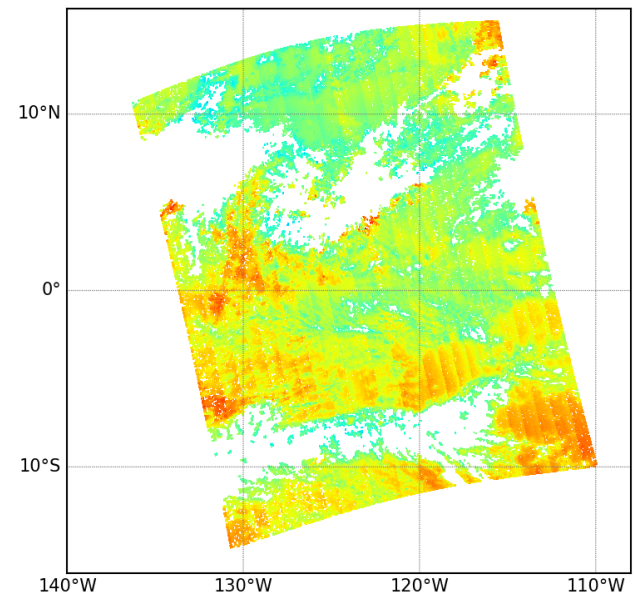

(c) Fitting residual (\%)

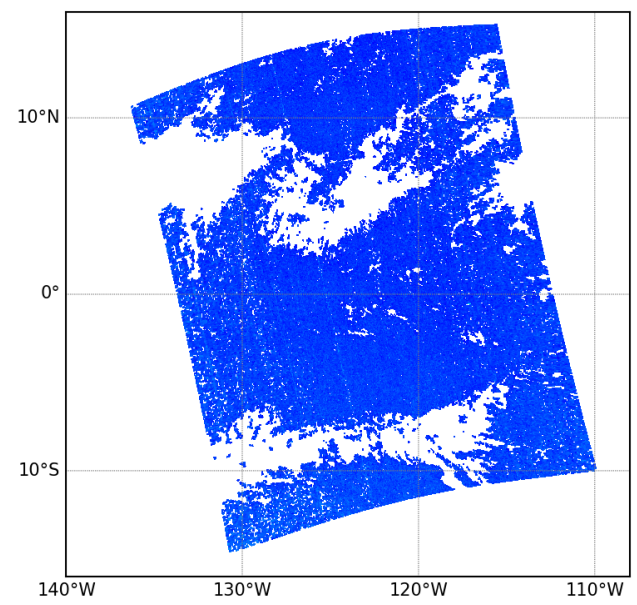

OE-based $\mathrm{SO}_{2}$ Retrieval from BAND2 Data

(b) Solution Error (DU)

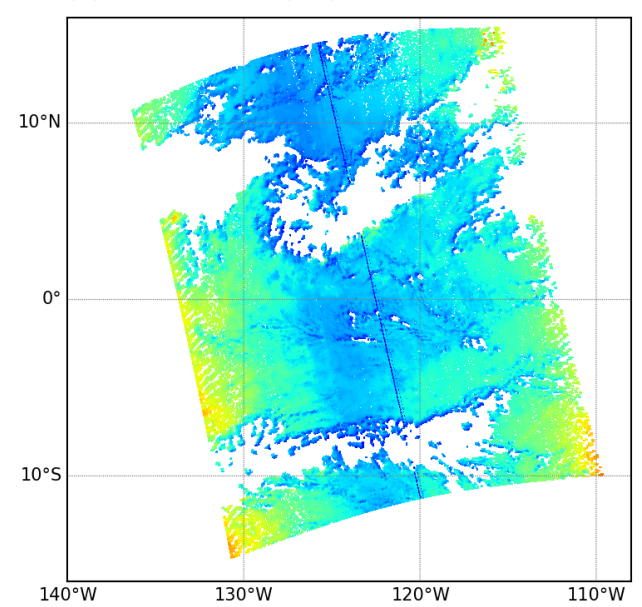

(d) Fitting Residual (\%)

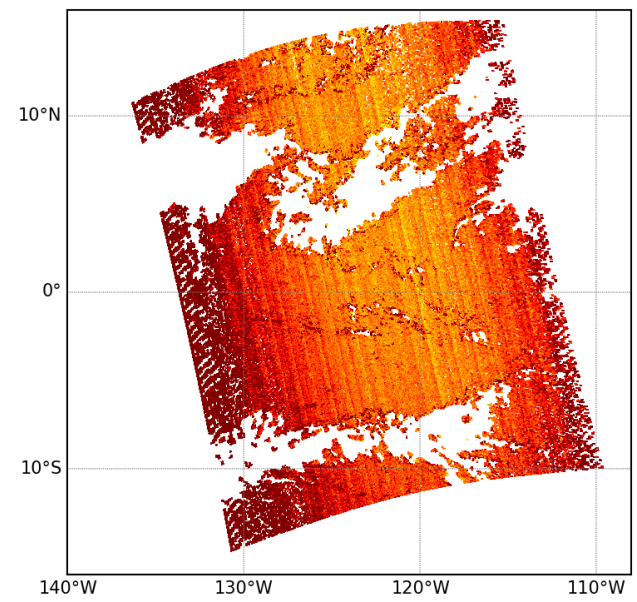

(DU)

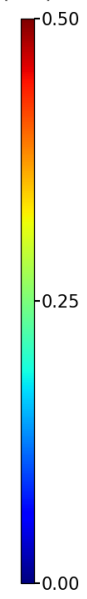

(\%)

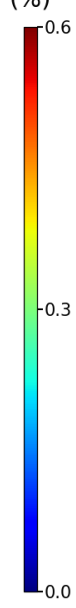

369 Figure S12. The solution error in (a) SO2-OE product retrieved from BAND 3 data and (b) OE-

370 based $\mathrm{SO}_{2}$ retrieval from BAND 2 data on June 16, 2019. (c) and (d) same as (a) and (b), but for

371 the average fitting residuals. 
(a) 2019

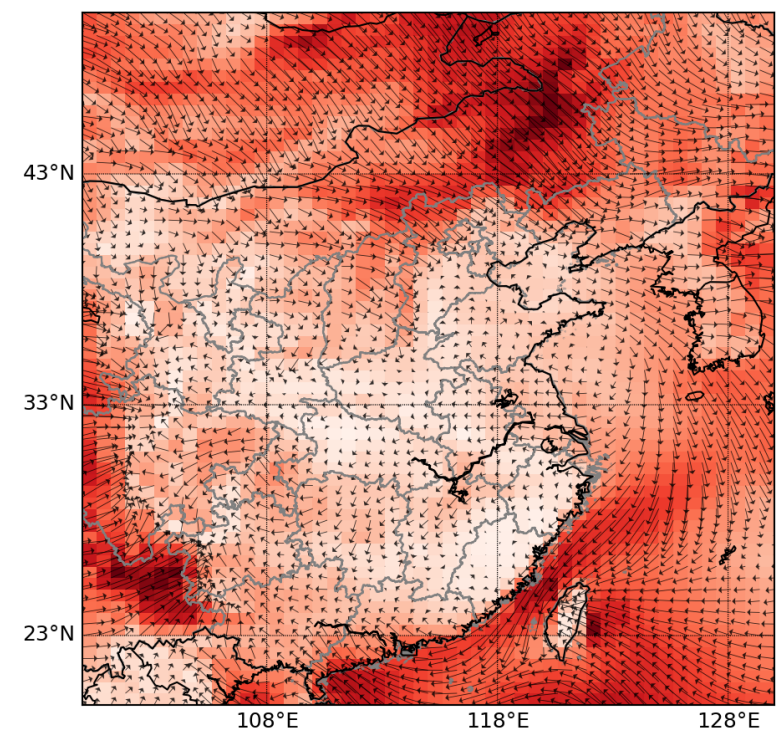

(c) 2019

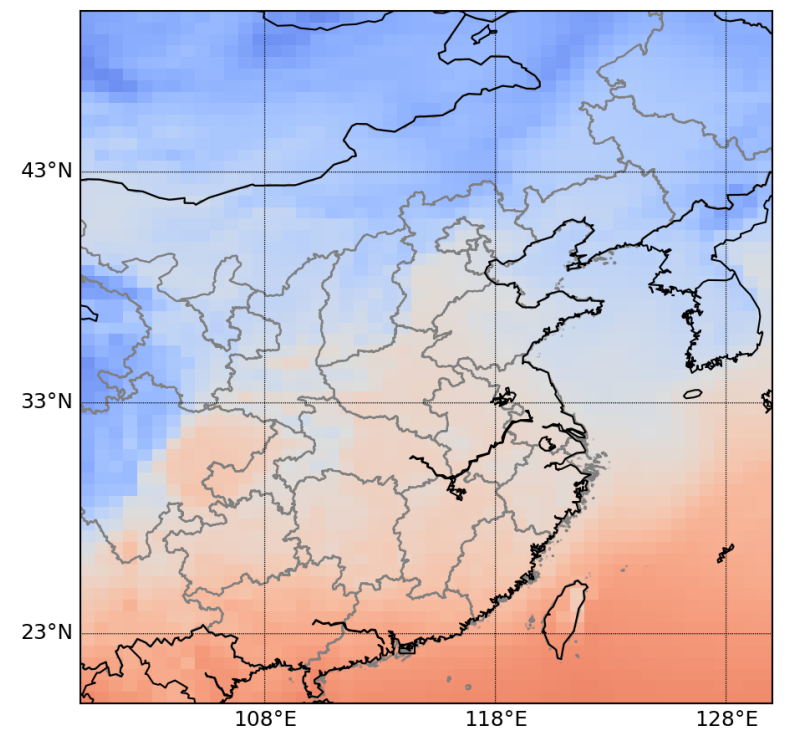

10 meter wind speed $(\mathrm{m} / \mathrm{s})$

(b) 2020

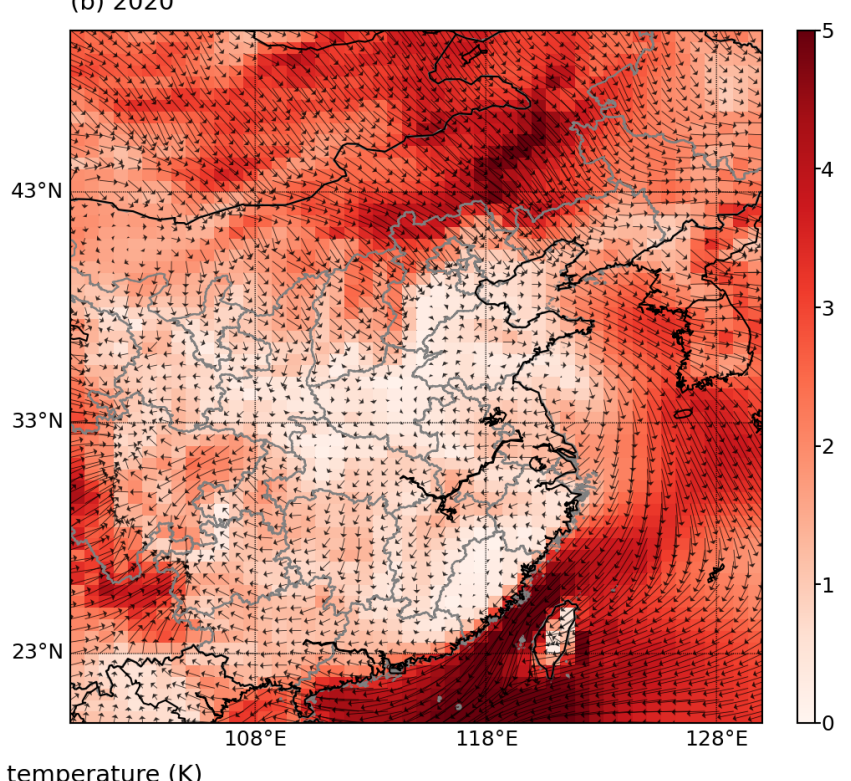

(d) 2020

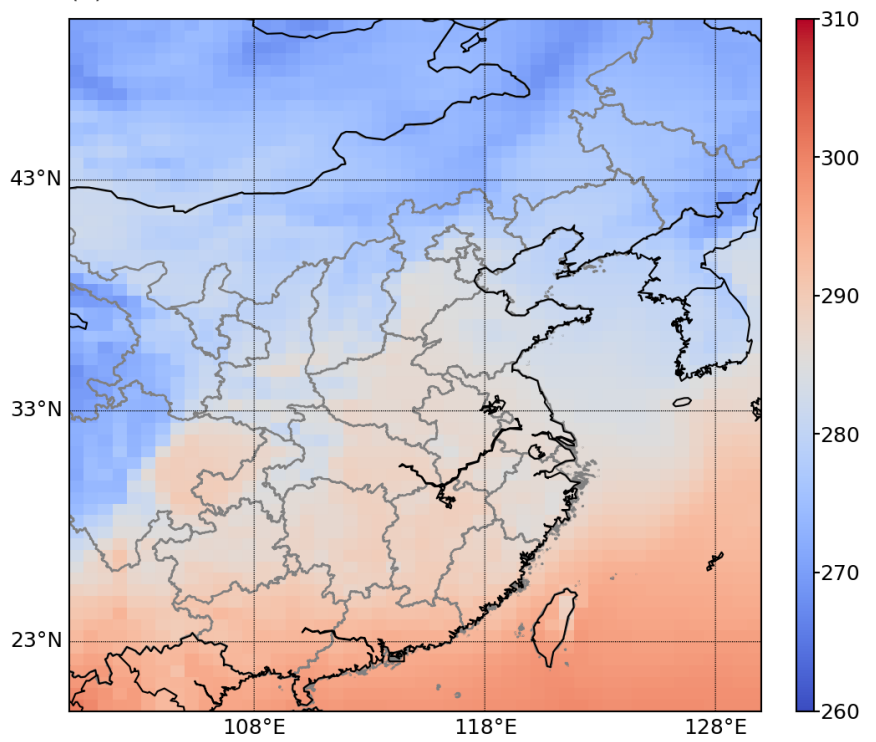

373 Figure S13. March-to-April monthly average 10-meter wind speed and direction, and 2-meter

374 temperature from MERRA-2 reanalysis monthly meteorological products in 2020 and the same

375 period in 2019 in Eastern China. 
(a) 2019

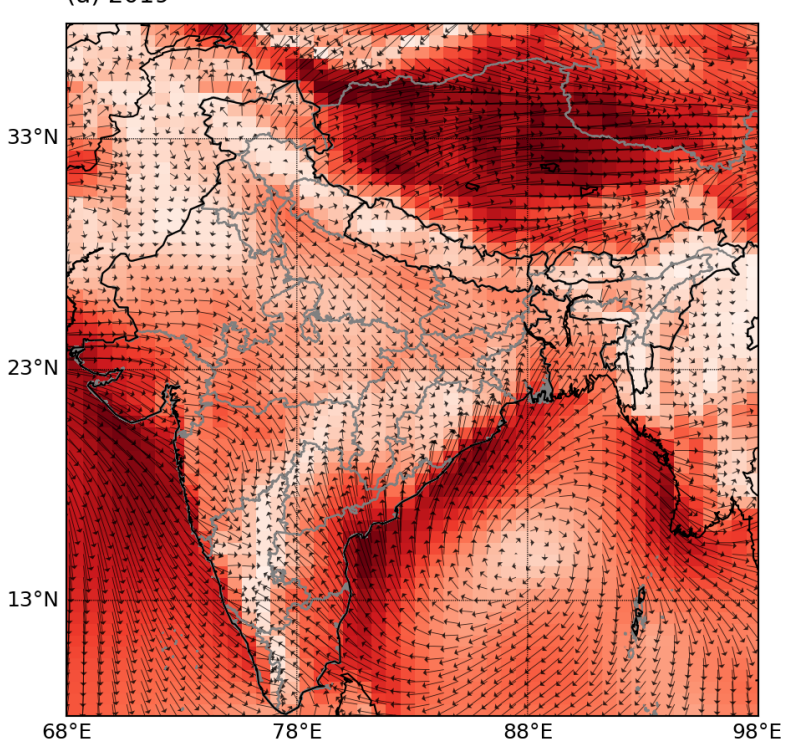

10 meter wind speed $(\mathrm{m} / \mathrm{s})$

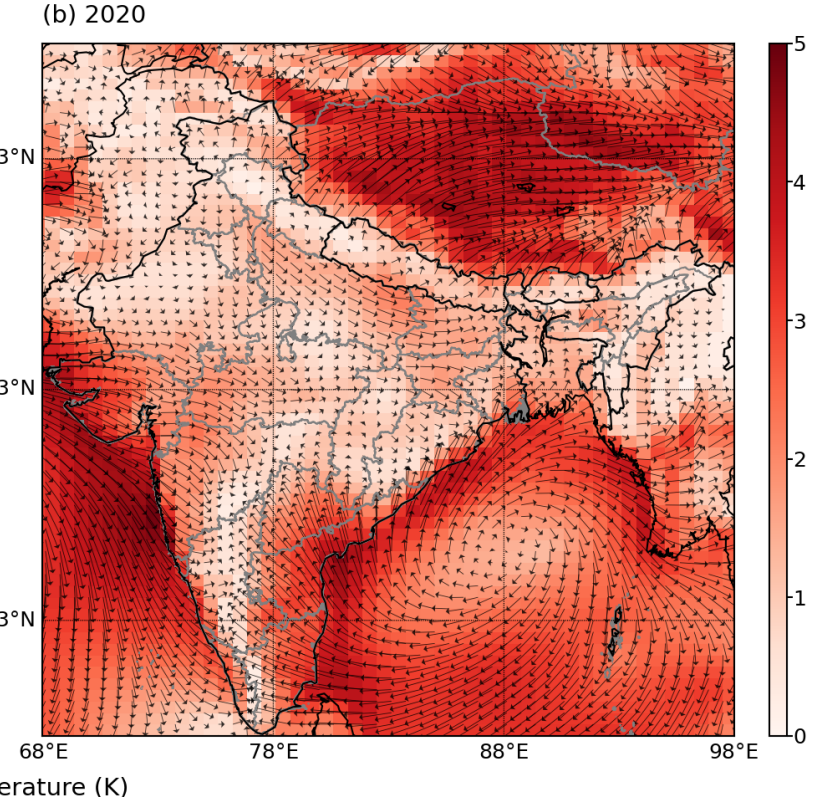

(c) 2019

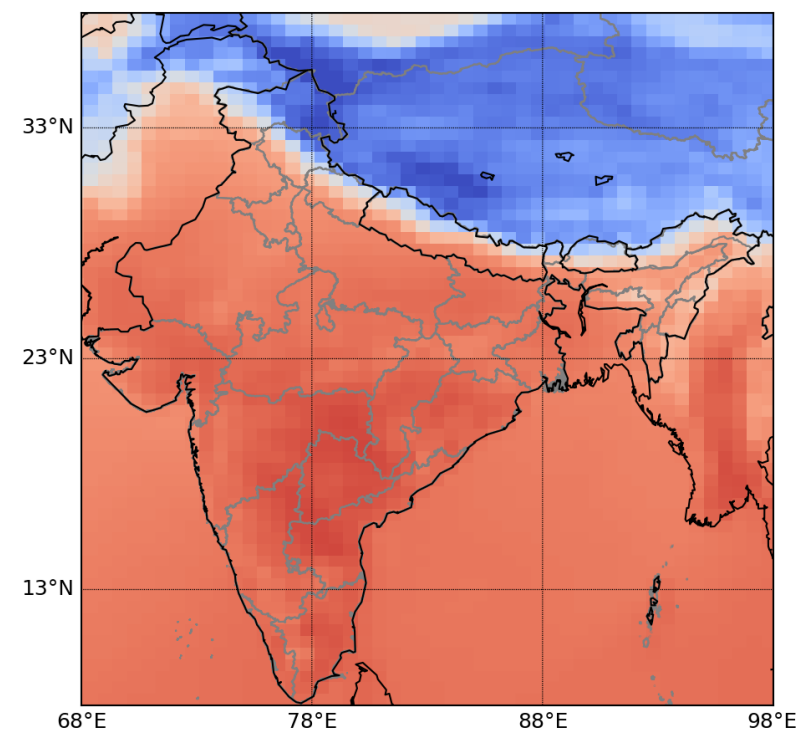

(d) 2020

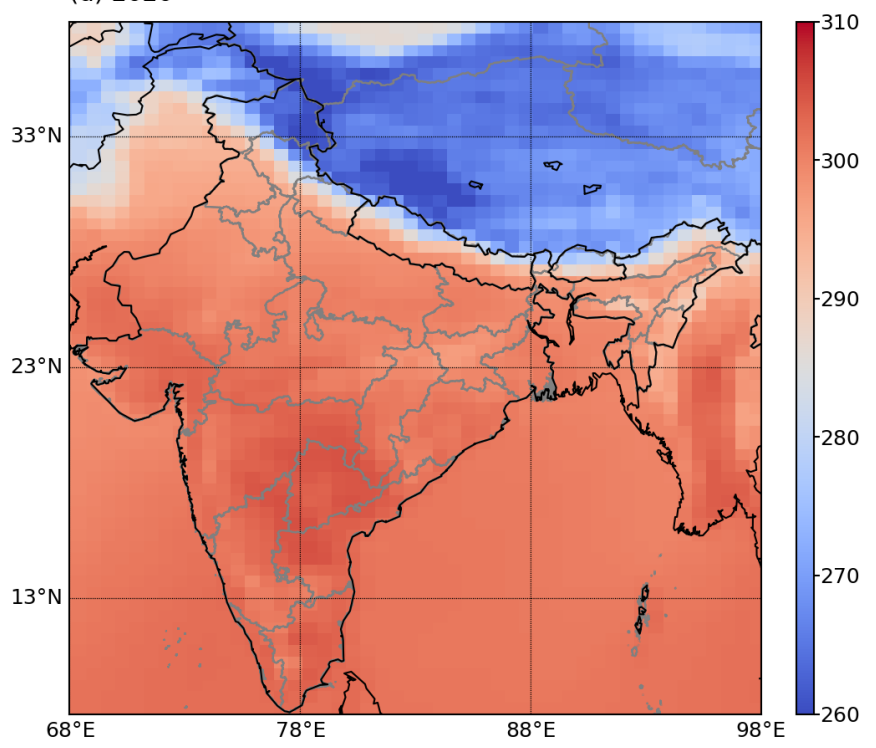

377 Figure S14. Same as Figure S13, but for the meteorological conditions in India. 
Eastern China

(a.1) CNEMC Stations

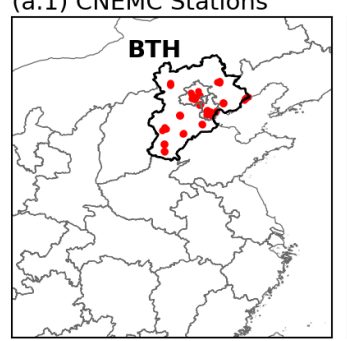

(a.2) Industry Bases

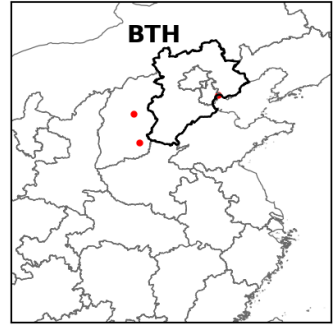

(c.1) Shanxi Taiyuan Industry Bases China

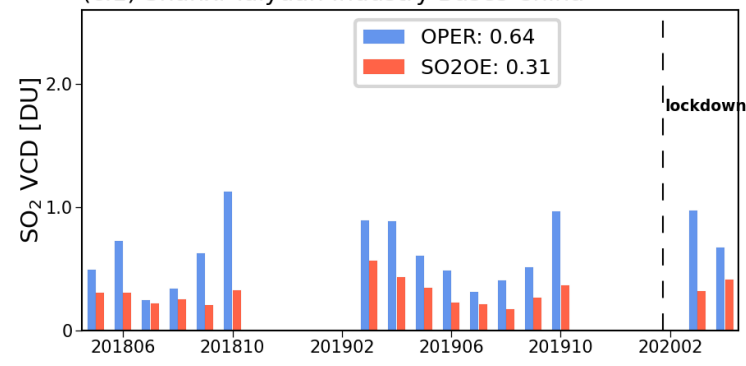

(c.2) Shanxi Changzhi Industry Bases China

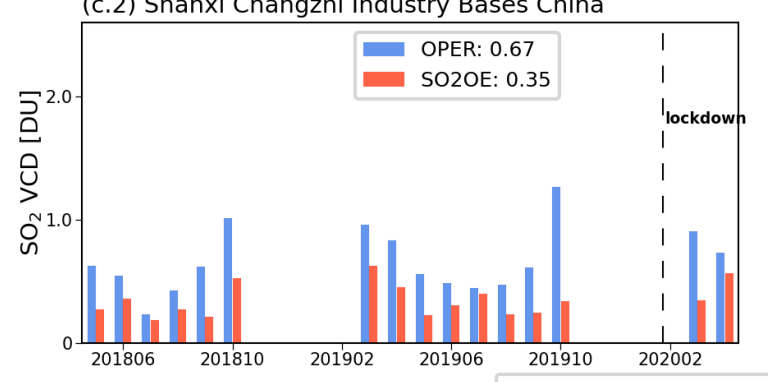

India

(b.1) CPCB Station

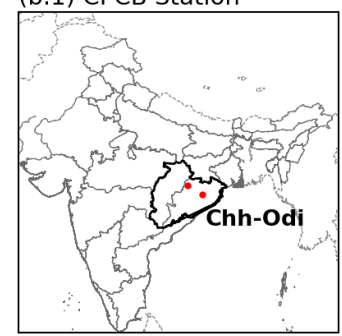

(b.2) Coal Power Plants

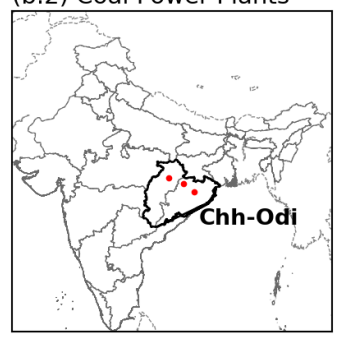

(d.1) Sterlite (Jharsuguda) Coal Mega Power Plant India

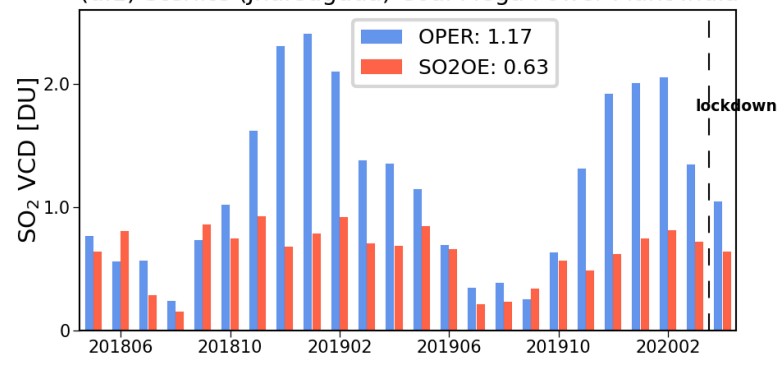

(d.2) Korba STPS Coal Power Plant India

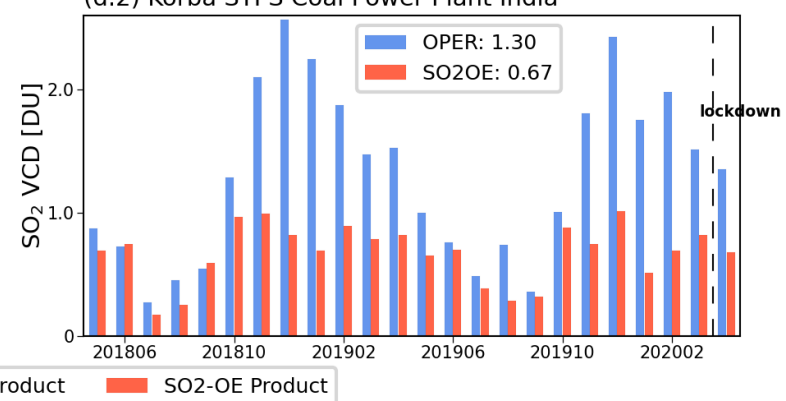

Figure S15. Positions of (a.1) CNEMC stations in BTH and (a.2) industry bases in Eastern China. monthly average $\mathrm{SO}_{2}$ columns (DU) from $\mathrm{SO} 2-\mathrm{OE}$ product (red bars) and $\mathrm{S}-5 \mathrm{P}$ operational $\mathrm{SO}_{2}$ product (blue bars) in Shanxi Taiyuan Industry Bases in China. (c.2), (d.1) and (d.2) same as (c.1), but for the time series of $\mathrm{SO}_{2}$ columns in Shanxi Changzhi Industry Bases in China, Sterlite 


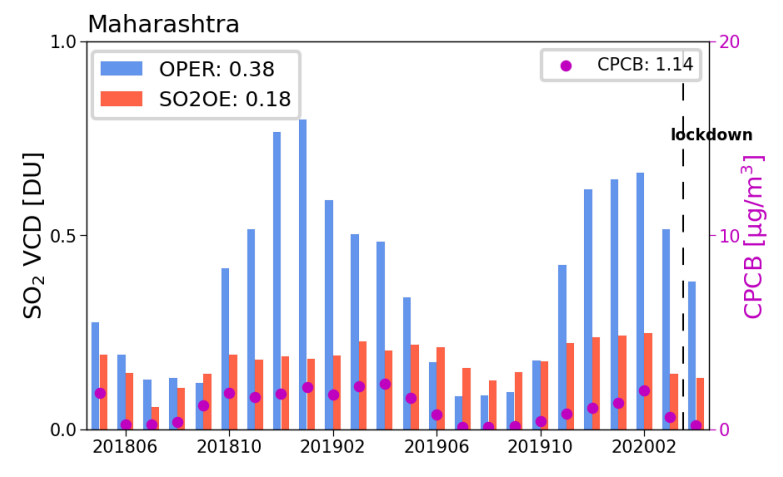

392 Figure S16. Time Series of monthly average SO2 columns (DU) from SO2-OE product (red bars)

393 and from S-5P operational product (blue bars), and average SO2 surface concentrations $\left(\mu \mathrm{g} \mathrm{m}^{-3}\right)$

394 from CPCB measurements (magenta dots) in Maharashtra, India. 
413 (1) Hong, Q.; Liu, C.; Hu, Q.; Xing, C.; Tan, W.; Liu, H.; Huang, Y.; Zhu, Y.; Zhang, J.; Geng, T.; Liu, J. Evolution of the Vertical Structure of Air Pollutants during Winter Heavy Pollution Episodes: The Role of Regional Transport and Potential Sources. Atmos.

(2) Javed, Z.; Liu, C.; Khokhar, M.F.; Xing, C.; Tan, W.; Subhani, M.A.; Rehman, A.; Res. 2019, 228, 206-222. 305.

(3) Hönninger, G.; Friedeburg, C. v.; Platt, U. Multi Axis Differential Absorption Spectroscopy (MAX-DOAS). Atmos. Chem. Phys. 2004, 4, 231-245.

(4) Loyola, D.G.; García, S.G.; Lutz, R.; Argyrouli, A.; Romahn, F.; Spurr, R.J.D.; Algorithms from TROPOMI on Board Sentinel-5 Precursor. Atmos. Meas. Tech. 2018, 11, 409-427.

Bak, J.; Liu, X.; Kim, J.; Haffner, D.P.; Chance, K.; Yang, K.; Sun, K. Characterization and Correction of OMPS Nadir Mapper Measurements for Ozone Profile Retrievals. Atmos. Meas. Tech. 2017, 10, 4373-4388.

Brion, J.; Chakir, A.; Daumont, D.; Malicet, J.; Parisse, C. High-Resolution Laboratory Absorption Cross Section of O3. Temperature Effect. Chem. Phys. Lett. 1993, 213, 610613. 
433 (7) Wang, S.; Streets, D.G.; Zhang, Q.; He, K.; Chen, D.; Kang, S.; Lu, Z.; Wang, Y. Satellite

Detection and Model Verification of NOx Emissions from Power Plants in Northern

China. Environ. Res. Lett. 2010, 5, 044007.

(8) Bogumil, K.; Orphal, J.; Homann, T.; Voigt, S.; Spietz, P.; Fleischmann, O.C.

Measurements of Molecular Absorption Spectra with the SCIAMACHY Pre-Flight

Model: Instrument Characterization and Reference Data for Atmospheric Remote-Sensing in the 230-2380 Nm Region. J. Photochem. Photobiol. A Chem. 2003, 157, 167-184.

(9) McLinden, C.A.; Olsen, S.C.; Hannegan, B.; Wild, O.; Prather, M.J.; Sundet, J.

Stratospheric Ozone in 3-D Models: A Simple Chem- Istry and the Cross-tropopause Flux. J. Geophys. Res. Atmos. 2000, 105, 14653-14665.

(10) Wilmouth, D.M.; Hanisco, T.F.; Donahue, N.M.; Anderson, J.G. Fourier Transform

(11) Meller, R.; Moortgat, G.K. Temperature Dependence of the Absorption Cross Sections of Formaldehyde between 223 and $323 \mathrm{~K}$ in the Wavelength Range 225-375 Nm. J. A 1999, 103, 8935-8945.

(12) Liu, X.; Bhartia, P.K.; Chance, K.; Spurr, R.J.D.; Kurosu, T.P. Ozone Profile Retrievals from the Ozone Monitoring Instrument. Atmos. Chem. Phys. 2010, 10, 2521-2537. 
Measurements and Application to Ozone Profile Retrievals. J. Geophys. Res. Atmos. 2012, $117,1-16$.

(14) McPeters, R.D.; Labow, G.J.; Logan, J.A. Ozone Climatological Profiles for Satellite

(19) Beirle, S.; Lampel, J.; Lerot, C.; Sihler, H.; Wagner, T. Parameterizing the Instrumental

Retrieval Algorithms. J. Geophys. Res. Atmos. 2007, 112, 1-9.

(15) Zhao, F.; Liu, C.; Cai, Z.; Liu, X.; Bak, J.; Kim, J.; Hu, Q.; Xia, C.; Zhang, C.; Sun, Y.; Wang, W.; Liu, J. Ozone Profile Retrievals from TROPOMI: Implication for the Variation of Tropospheric Ozone during the Outbreak of COVID-19 in China. Sci. Total Environ. 2021, 764, 142886.

(16) Munro, R.; Lang, R.; Klaes, D.; Poli, G.; Retscher, C.; Lindstrot, R.; Huckle, R.; Lacan, A.; Grzegorski, M.; Holdak, A.; Kokhanovsky, A.; Livschitz, J.; Michael Eisinger. The GOME-2 Instrument on the Metop Series of Satellites: Instrument Design, Calibration, and Level 1 Data Processing - an Overview. Atmos. Meas. Tech. 2016, 9, 1279-1301.

(17) Bak, J.; Liu, X.; Sun, K.; Chance, K.; Kim, J.H. Linearization of the Effect of Slit Function Changes for Improving Ozone Monitoring Instrument Ozone Profile Retrievals. Atmos. Meas. Tech. 2019, 12, 3777-3788.

(18) Chance, K.; Kurucz, R.L. An Improved High-Resolution Solar Reference Spectrum for Earth's Atmosphere Measurements in the Ultraviolet, Visible, and near Infrared. J. Quant. Spectrosc. Radiat. Transf. 2010, 111, 1289-1295.

Spectral Response Function and Its Changes by a Super-Gaussian and Its Derivatives. Atmos. Meas. Tech. 2017, 10, 581-598. 
474 (20) Smeets, J.; Kleipool, Q.; Hees, R. van; Sneep, M. Readme for TROPOMI Instrument 475 Spectral Response Functions; 2018,.

476 (21) Kleipool, Q.L.; Dobber, M.R.; de Haan, J.F.; Levelt, P.F. Earth Surface Reflectance Climatology from 3 Years of OMI Data. J. Geophys. Res. Atmos. 2008, 113, 1-22.

(22) Liu, X.; Chance, K.; Sioris, C.E.; Spurr, R.J.D.; Kurosu, T.P.; Martin, R. V.; Newchurch, M.J. Ozone Profile and Tropospheric Ozone Retrievals from the Global Ozone Monitoring Experiment: Algorithm Description and Validation. J. Geophys. Res. Atmos.

(23) McLinden, C.A.; Fioletov, V.; Boersma, K.F.; Kharol, S.K.; Krotkov, N.; Lamsal, L.; 2005, 110, 1-19.

(24) Sioris, C.E.; Boone, C.D.; Bernath, P.F.; Zou, J.; McElroy, C.T.; McLinden, C.A.

(25) Theys, N.; Smedt, I. De; Lerot, C.; Yu, H.; Roozendael, M. Van. S5P/TROPOMI SO2 ATBD. BIRA-IASB 2020, 1-69.

(26) Puk̄īe, J.; Kühl, S.; Deutschmann, T.; Platt, U.; Wagner, T. Extending Differential Optical Absorption Spectroscopy for Limb Measurements in the UV. Atmos. Meas. Tech. 2010, 3, $631-653$. 
(27) Vountas, M.; Rozanov, V. V.; Burrows, J.P. Ring Effect: Impact of Rotational Raman Scattering on Radiative Transfer in Earth's Atmosphere. J. Quant. Spectrosc. Radiat. Transf. 1998, 60, 943-961.

(28) Spurr, R.; de Haan, J.; van Oss, R.; Vasilkov, A. Discrete-Ordinate Radiative Transfer in a Stratified Medium with First-Order Rotational Raman Scattering. J. Quant. Spectrosc. Radiat. Transf. 2008, 109, 404-425.

(29) Williams, J.E.; Folkert Boersma, K.; Le Sager, P.; Verstraeten, W.W. The HighResolution Version of TM5-MP for Optimized Satellite Retrievals: Description and Validation. Geosci. Model Dev. 2017, 10, 721-750.

(30) Nowlan, C.R.; Liu, X.; Chance, K.; Cai, Z.; Kurosu, T.P.; Lee, C.; Martin, R. V. Retrievals of Sulfur Dioxide from the Global Ozone Monitoring Experiment 2 (GOME-2) Using an Optimal Estimation Approach: Algorithm and Initial Validation. J. Geophys. Res. Atmos. 2011, 116, 1-20.

(31) Loyola, D.; Lutz, R.; Argyrouli, A.; Spurr, R. S5P/TROPOMI ATBD Cloud Products. DLR 2020, 